Western University Scholarship@Western

Research Program. Impact of the Public Sector on Research Program. Impact of the Public Sector on Local Economies Discussion Papers

Local Economies

1977

\title{
Urban Structure, Gas Prices, and the Demand for Transportation
}

Arthur J. Robson

David T. Scheffman

Follow this and additional works at: https://ir.lib.uwo.ca/economicsipsle_dp

Part of the Economics Commons

\section{Citation of this paper:}

Robson, Arthur J., David T. Scheffman. "Urban Structure, Gas Prices, and the Demand for Transportation." Research Program. Impact of the Public Sector on Local Economies Discussion Papers, 019. London, ON: Department of Economics, University of Western Ontario (1977). 


\section{Discussion Paper 019 \\ URBAN STRUCTURE, GAS PRICES, AND THE \\ DEMAND FOR TRANSPORTATION}

Arthur J. Robson

David T. Scheffman

\section{RESEARCH PROGRAM: IMPACT OF THE PUBLIC SECTOR ON LOCAL ECONOMIES}

i

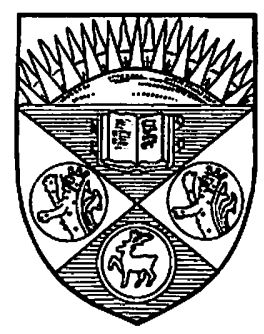

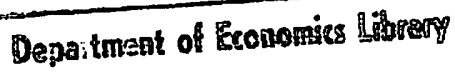
MAY 251977

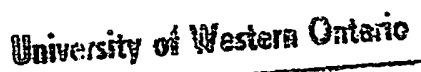

Department of Economics The University of Western Ontario London Ontario Canada 


\section{Discussion Paper 019 \\ URBAN STRUCTURE, GAS PRICES, AND THE DEMAND FOR TRANSPORTATION}

Arthur J. Robson

David T. Scheffman

May, 1977 
URBAN STRUCTURE, GAS PRICES, AND THE

DEMAND FOR TRANSPORTATION*

Arthur J. Robson

David T. Scheffman

\section{Introduction}

What impact will an increase in the price of gasoline have upon demand for transportation? In this paper, a single strategy for consumers to reduce demand is considered--the reduction of the length of the journey to work. Such reduction involves a greater concentration on the residential pattern. This is possible to a certain extent within existing structures and to a larger extent if reconstruction takes $\mathrm{place}$. This paper abstracts from other strategies to reduce demand such as curtailing recreational use of the automobile, switching to a smaller car, etc.

The response of total mileage driven to an increase in the cost per mile is considered for an abstract residential city where all inhabitants receive the same income. The analysis treats transportation not as a good desired for its own sake, but rather as a good needed so that an individual can consume space while retaining access to the place of employment. For the sake of tractability, the total cost of transportation is assumed to be small relative to the income of a typical individual. This is done instead of limiting arbitrarily the class of utility functions considered. The characteristics of an individual's demand for space are shown to determine the response of total mileage to an increase in the cost per mile. These results are derived under the assumption that there is a boundary rent condition and hence a flexible overall radius. The assumption 
is made that rent is equally redistributed to all residents and hence forms part of their income. Although this is more reasonable than supposing there is a class of absentee landlords, there are usually analytic difficulties. The problem is soluble in this approximate case, however. Finally, a numerical projection is made for the effect of gasoline prices on the demand for transportation. This is based on data for American cities.

\section{The Model}

Consider an abstract model of residential location within an urban area. (Similar models are studied by Mills [3], Solow [5], and Dixit [2], among others.) The city is circularly symmetric and includes suburbs surrounding a Central Business District (CBD). The city has an overall radius of $R$ and the $C B D$ a radius of $C$, say. Any internal structure of the $C B D$ is neglected here. $A 11$ household heads commute to the centre of the CBD every working day. Circumferential travel is assumed unnecessary, but radial travel costs $t$ dollars per year per mile that the household lives from the centre. All households have the same utility function

$$
u=u(s, z)
$$

where $s$ is residential space (in square miles) and $z$ is a composite good representing all other non-spatial commodities (in dollars). The utility function is quasi-concave and $s$ and $z$ are taken to be normal. Each individual has the same income of $y$ dollars per year. The budget constraint for a household locating $x$ miles from the centre is

$$
y=r(x) s+z+t \cdot x
$$


where $r(x)$ is the rent at $x$ in dollars per square mile per year, which is as yet undetermined. For a given distance $x$ and rent $r(x)$, an individual maximizes utility, (1), subject to his budget constraint, (2), over choice of $s$ and $z$. These optimum choices, $s(x)$ and $z(x)$, say, are functions of the net income at $x, y-t x$, and of the rent $r(x)$. The utility attained is a function of $y-t x$ and $r(x)$ :

$$
V-V(y-t x ; r(x))
$$

where this is the indirect utility function. (This approach was originated by Solow [6].) The indirect utility function has the property that

$$
s(x)=-\frac{v_{r}(y-t x ; r(x))}{V_{y}(y-t x ; r(x))}
$$

What about choice of $x$ by a household? Competition ensures that households with the same income attain the same level of utility $(r(x)$ adjusts to make this true). Hence

$$
V(y-t x ; r(x))=\bar{V}
$$

where $\bar{V}$ is independent of $x$, but undetermined so far. Equation (5) implies

$$
r^{\prime}(x)=t \frac{V_{y}(y-t x ; r(x))}{V_{r}(y-t x ; r(x))}=\frac{-t}{s(x)}
$$

The land available for residents and the total population determine the level of utility, $\bar{v}$, reached by all households. Suppose, for convenience, that a constant fraction of arc, $a$, is allocated to residences. A more general assumption causes no particular difficulties, but the fraction of land used by residences is usually not far from constant in real cities. 
(The remaining fraction of arc might be used for roads, or it might be water if the city is on the coast.) If the number of households living between $x$ and $x+d x$ is $n(x) d x$, equality between land supplied and demanded between $x$ and $x+d x$ implies

$$
n(x) s(x)=2 \pi a x
$$

Suppose that the total population of the city is $N$ households, so

$$
N=\int_{C}^{R} n(x) d x=-2 \pi a \int_{C}^{R} x \frac{V_{y}(y-t x ; r(x))}{\left.V_{r}^{*} y-t x ; r(x)\right)} d x
$$

Since $r(x)$ is determined by (5) in terms of $\bar{v},(8)$ determines $\bar{V}$, if the overall radius $R$ of the city is given. However, it is realistic to assume that $R$ is determined by a boundary rent condition. If the value of 1 and in some alternative use, say agriculture, is fixed at $r^{*}$, and the residential rent function $r(x)$ declines with $x$, competition ensures that

$$
r(r)=r^{*}
$$

Suppose each household head makes $A$ round trips to the centre each year. The total mileage driven by all households in a year is

$$
D=2 A \int_{C}^{R} n(x) x d x=-4 \pi A a \int_{C}^{R} x^{2}\left\{\frac{V_{y}(y-t x ; r(x))}{V_{r}(y-t x ; r(x))}\right\} d x
$$

where $r(x)$ satisfies (5) and (8).

The key relationship from the point of view of the present paper is the dependence of $D$ upon $t$, the per mile cost of transportation. In full generality, this problem is somewhat intractable. One approach would be to limit the utility function to be Cobb-Douglas, for example. The 
approach adopted here, however, is to retain a general utility function, but to consider an approximation for small $t$. Then light is shed on the. general characteristics of demand for space which are relevant. A further approximation, for convenience only, is to assume that the radius of the CBD, $C$, can be neglected in comparison with the overall radius, $R$. $D$ is given to first-order approximation as

$$
D=D^{*}+t D_{t}
$$

and the percentage change in $D$ for a small change in $t$, near $t=0$, is

$$
\frac{\Delta D}{D} \simeq \lim _{t \rightarrow 0}\left[\frac{1}{D} \frac{d D}{d t}\right] \Delta t=\frac{D_{t}}{D^{\star}} \Delta t
$$

To evaluate $D^{*}$, consider the case $t \rightarrow 0$. There is a rental value for alternative use of the land of $r^{*}$, as before. The optimum choices for $s$ and $z$ follow from (4):

$$
s^{*}=-\frac{V_{r}\left(y, r^{*}\right)}{V_{y}\left(y, r^{*}\right)}, \quad z^{*}=y-r^{*} s^{*}
$$

which are independent of $x$. Equality of land supplied and demanded determines $R^{*}$ :

$$
\pi a R^{*}=N s^{*}=-N \frac{V_{r}\left(y ; r^{*}\right)}{V_{y}\left(y ; r^{*}\right)}
$$

Hence $D^{*}$ is

$$
D *=\frac{4 \pi A_{a R}{ }^{3}}{3 s^{*}}
$$


Consider now evaluation of $D_{t}$. The following first-order expressions hold,

$$
\begin{aligned}
s(x) & =s^{*}+t s_{t}(x) \\
R & =R^{*}+t R_{t}
\end{aligned}
$$

and

$$
r(x)=r^{*}+\operatorname{tr}_{t}(x)
$$

From (6) in this case,

$$
r_{t}^{\prime}(x)=-\frac{1}{s^{\star}}
$$

The boundary condition, (9), implies

$$
r_{t}\left(R^{*}\right)=0
$$

so that

$$
r_{t}(x)=\frac{R^{*}-x}{s^{*}}
$$

and rent rises as the cost per mile, $t$, rises.

The following question must now be answered: Who owns the city's land? Does rent reappear as income of individuals resident in the city or is it lost to a class of absentee landlords? To treat $y$ as fixed is to implicitly adopt the absentee landlord assumption. Redistribution of rent is a more reasonable assumption, and then changes in aggregate rent will be reflected in changes in per capita income, $y$. A further advantage of the approximation made is that the redistribution of rent introduces no particular difficulties, as noted before. 
Suppose then rent is redistributed to residents. An individual's income $y$ is

$$
y=\bar{y}+L / N
$$

where $\bar{y}$ is a fixed component and $L$ is the total rent. Hence in addition to the first-order approximations of (16),

$$
\begin{aligned}
& L=L^{*}+t L_{t} \\
& y=y^{*}+t y_{t}
\end{aligned}
$$

and

$$
y_{t}=L_{t} / N
$$

When the city shrinks, for example, ownership of the land converted is retained by residents of the city. Then $L$ includes payments for the use of this land, so

$$
L=2 \pi \cdot a \int_{0}^{R} x r(x) d x+\pi a\left(R^{*}-R^{2}\right) r^{*}
$$

and

$$
L_{t}=2 \pi \cdot a \int_{0}^{R^{\star}} x r_{t}(x) d x
$$

since two other terms cancel. However, using (19) for $r_{t}(x)$,

$$
L_{t}=\frac{\pi a R^{3}}{3 s^{\star}}
$$

and hence

$$
y_{t}=R^{*} / 3
$$


since $N s^{*}=\pi \cdot a R^{*}$. Differentiating (4) with respect to $t$, and using (19) and (23) it can be shown that

$$
s_{t}(x)=\frac{\alpha x}{s^{*}}+R^{*}\left[-\frac{1}{3^{\alpha}}+\frac{2}{3} \frac{\partial s^{*}}{\partial r}\right]
$$

where

$$
\alpha=-\left(\frac{\partial S^{*}}{\partial r}+s^{*} \frac{\partial S^{*}}{\partial y}\right)>0
$$

is the absolute value of the slope of compensated demand for space. Hence $s_{t}(x)<0$ and space per capita declines as $t$ increases. Now from (8) since $N$ is fixed, it follows that

$$
R_{t}=\frac{R^{*}}{6 s^{*}}\left\{\frac{\partial s^{*}}{\partial r}-s^{*} \frac{\partial s^{*}}{\partial y}\right\}
$$

so the radius shrinks as $t$ increases. Finally it can be shown that 1

$$
\frac{D_{t}}{D^{\star}}=-\frac{R^{\star}}{12 y^{\star}}\left\{3 \frac{E_{S, r}}{K_{s}}+E_{s, y^{\prime}}\right\}
$$

where

$$
\begin{aligned}
E_{s, r} & =-\frac{r^{*}}{s^{\star}} \frac{\partial s^{*}}{\partial r}>0 \\
E_{s, y} & =\frac{y}{s^{*}} \frac{\partial s^{*}}{\partial y}>0 \\
K_{s} & =\frac{r^{*} s^{*}}{y}
\end{aligned}
$$

In other words, cities that are physically large or have low per capita incomes tend to exhibit a high percentage decline in mileage driven 
as the price of gasoline rises. However, cities with the same radius and per capita income, but different populations, exhibit the same percentage decline in total mileage. As to individual characteristics, a high income or price elasticity of demand for space is reflected in a high percentage decline in mileage. On the other hand, the greater the fraction of income spent on space, the smaller the percentage decline in mileage driven.

What is the order of magnitude of the change in mileage driven predicted by the model for an increase in the price of gasoline? As long as the direct expenditure plus time cost for transportation is small in relation to the budget of the typical individual, the model applies. If the price of gasoline increases, the increase in the cost per mile will be proportional.

Consider then estimates of the parameters involved in (26). Suppose that the city has a radius of 20 miles and family income of $\$ 12,500$. Assume the price and income elasticities of demand for space are unitary. (This is roughly consistent with estimated elasticities for housing as in De Leeuw, 1971. Also Muth, 1971, assigns unitary elasticities for purposes of prediction in spite of lower estimated values.) The crucial parameter is then the fraction of income spent on space per se. Muth (1971) believes that the fraction of housing expenditure going to 1 and is near 0.10 , for new units. The Census suggests that the fraction of income spent on housing is about 0.15 , so the fraction of income spent on space is 0.015 . Consider then a 10 cents per (U.S.) gallon increase in the price of gasoline, and suppose each household makes 250 round-trips to the centre per year, in an automobile getting 16 miles per gallon. Then (26) implies

$$
\frac{D_{t}}{D^{\star}} \Delta t=-8.38 \%
$$


This, then, is the predicted percentage change in mileage occurring after residential relocation has taken place. Although it is a reasonably substantial effect it would take a long time to fully obtain.

\section{Conclusions}

The paper investigates how residential relocation reduces demand for transportation when the price of gasoline rises.

An abstract model of residential location is considered where identical residents had identical incomes. Assuming that the budget share of transportation is small, a formula is derived for the percentage decline in total mileage as a result of an increase in the cost per mile. Rent is redistributed to the residents. The percentage decline in total mileage is greater, the more elastic demand for space is either with respect to rent or income. The percentage decline is less, however, the larger the budget share of space, or the larger the per capita income. The percentage decline is independent of population, per se, but is larger, the larger the radius of the city. Using reasonable estimates of the parameters involved for a SMSA of radius 20 miles, it is shown that the model implies roughly an $8 \%$ long-run reduction in mileage, for a 10 cent a gallon increase in the price of gasoline. This large effect arises from the small estimated share of space of income. 
FOOTNOTES

*A grant from General Motors Corporation is gratefully acknowledged. The views presented, however, are solely the authors'.

IUnder the assumption that rents are lost to a class of absentee landlords, or that income $y$ is fixed, the corresponding formula can be shown to be

$$
\frac{D_{t}}{D^{*}}=-\frac{R^{*}}{4 y}\left\{\frac{E_{s, r}}{K_{s}}+E_{s, y}\right\}
$$

which is close to (27) for small values of $K_{s}$. 
REFERENCES

[1] F. De Leeuw, "The Demand for Housing: A Review of Cross-Section Evidence", Review of Economics and Statistics 53 (1971), 1-10.

[2] A. Dixit, "The Optimum Factory Town", Be11 Journal of Economics and Management Sciences 4 (1973), 637-651.

[3] E. S. Mills, Urban Economics, Scott Foresman, Glenview, Illinois (1972).

[4] R. Muth, "The Derived Demand for Urban Residential Land", Urban Studies 8 (1971), 243-254.

[5] R. M. Solow, "Congestion, Density and The Use of Land in Transportation", Swedish Journal of Economics 74 (1972), 161-173.

[6] R. M. Solow, "On Equilibrium Models of Urban Location", in Essays in Modern Economics, Parkin and Nobay (eds.), Longman, London (1973). 
RESEARCH PROGRAM:

IMPACT OF THE PUBLIC

SECTOR ON LOCAL ECONOMIES

The Department of Economics, University of Western Ontario, has recently mounted a long-term research program on the Impact of the Public Sector on Local Economies. The program publishes Discussion Papers and Research Studies. Copies may be obtained by writing:

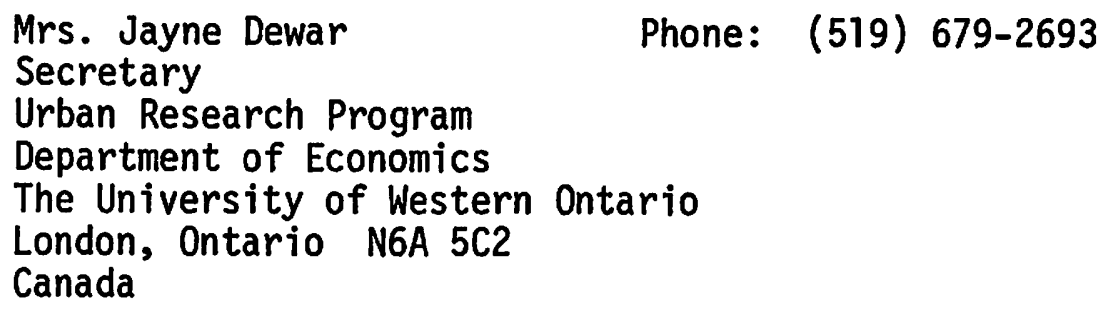

The following Discussion Papers and Research Studies are

\section{DISCUSSION PAPERS:}

* 001 P.T. Chinloy, "Hedonic Prices and Age Deterioration in Urban and Suburban Housing" (September 1975). [30 pp. - \$1.50]

002 M.W. Frankena, "Alternative Models of Rent Control" (September 1975).

003 J.R. Markusen and D.T. Scheffman, "Ownership Concentration and Market Power in Urban Land Markets" (October 1975).

004 A.J. Robson, "The Effect of Urban Structure on Ambient Pollution" (October 1975).

005 J.R. Markusen and D.T. Scheffman, "The Timing of Residential Land Development: A General Equilibrium Approach" (November 1975).

006 A.J. Robson, "Cost-Benefit Analysis and the Use of Urban Land for Transportation" (December 1975).

007 M.F. Goodchild and P.J. Booth, "Modelling Human Spatial Behavior in Urban Recreation Facility Site Location" (January 1976).

008 M.W. Johnson, "Consumer Location and Local Public Goods" (March 1976).

009 K.L. Avio and C.S. Clark, "The Supply of Property Offenses in Ontario" (Apri1 1976). 
010 P.T. Chinloy, "Depreciation, Adverse Selection and Housing Markets" (May 1976).

* 011 C.L. Poon, "An Economic Evaluation of Urban Railway Relocation" (September 1976). [32 pp. - \$1.60]

012 A.J. Robson, "Income Uncertainty and Urban Location" (September 1976).

013 M.W. Frankena, "An Error in Estimating Urban Density Functions Using Census Tract Data" (October 1976).

014 G.W. Davies, "The Demand for Automobiles in Canada" (December 1976).

015 M.W. Frankena, "The Demand for Urban Bus Transit in Canada" (December 1976).

016 A.J. Robson and D.T. Scheffman, "The Crunch, the Boom, and the Recreational Land Market" (January 1977).

017 A.G. Blomqvist and W. Haessel, "Small Cars, Large Cars, and the Price of Gasoline" (January 1977).

018 C.L. Poon, "Railway Externalities and Residential Property Prices" (February 1977).

019 A.J. Robson and D.T. Scheffman, "Urban Structure, Gas Prices, and the Demand for Transportation" (May 1977).

RESEARCH STUDIES:

01 G.W. Davies and P.L. Jackson, "A Model of the Urban Housing and Residential Land Markets" (September 1975).

02 G.P. Schaefer, "The Urban Area Production Function and the Urban Hierarchy: The Case of Saskatchewan" (October 1975).

03 C.L. Poon, "A Cost-Benefit Study of Urban Railway Relocation" (November 1976).

04 M.W. Frankena, "Urban Transportation Economics and Canadian Public Policy" (February 1977).

* This report is out-of-print. Xerox copies can be obtained for a minimal charge of $5 \$$ per page. 